Harvard Kennedy School Misinformation Review ${ }^{1}$

September 2021, Volume 2, Issue 5

Creative Commons Attribution 4.0 International (CC BY 4.0)

Reprints and permissions: misinforeview@hks.harvard.edu

DOI: https://doi.org/10.37016/mr-2020-80

Website: misinforeview.hks.harvard.edu

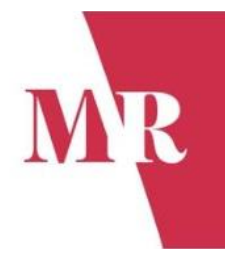

\title{
Research note: Understanding offline Covid-19 conspiracy theories: A content analysis of The Light "truthpaper"
}

This article explores the ways in which offline conspiracist material concerned with Covid-19 is presented and structured through a content analysis of The Light, a newspaper produced and distributed by activists in the U.K. Our analysis shows that conspiracy theories related to Covid-19 are included alongside a range of other, non-conspiracist content and that readers encounter these ideas in a format which closely resembles a conventional newspaper. We also find evidence that The Light includes content that is aimed at prompting participation and activism amongst adherents of conspiracy theories, rather than simply presenting information. These findings have implications for policymakers aiming to mitigate the effects of Covid-19 misinformation and provide a corrective to the focus of recent research on online dissemination of conspiracist material.

Authors: Rod Dacombe (1), Nicole Souter (2), Lumi Westerlund (2)

Affiliations: (1) Department of Political Economy, King's College London, UK, (2) Mansfield College, University of Oxford, UK How to cite: Dacombe, R., Souter, N., \& Westerlund, L. (2021). Research note: Understanding offline Covid-19 conspiracy theories: A content analysis of The Light "truthpaper." Harvard Kennedy School (HKS) Misinformation Review, 2(5).

Received: June 29 ${ }^{\text {th }}, 2021$. Accepted: September $1^{\text {st }}, 2021$. Published: September 17 $7^{\text {th }}, 2021$.

\section{Research questions}

- How are conspiracy theories concerned with Covid-19 structured and presented in offline media?

- How do offline conspiracist materials promote participation and activism?

\section{Essay summary}

- The Covid-19 pandemic has highlighted the potential for conspiracy theories to result in realworld harms. Many recent analyses of the dissemination of conspiracy theories point to the importance of social media and online sources in facilitating their spread.

- However, offline media are still used by conspiracy theorists to share conspiracist content. This article presents findings from a content analysis of The Light, a newspaper printed and distributed by activists throughout the U.K., in order to shed new light on the ways in which conspiracist content related to Covid-19 can be structured and presented through offline means.

- We find that The Light presents five kinds of content: (1) conspiracy theories related to Covid-19, (2) other, unrelated conspiracist content, (3) non-conspiracist content and misinformation related

\footnotetext{
${ }^{1}$ A publication of the Shorenstein Center on Media, Politics and Public Policy at Harvard University, John F. Kennedy School of Government.
} 
to Covid-19, (4) other non-conspiracist news items, and (5) paid advertisements.

- This content is also intended to be participatory, and each content type includes frequent explicit calls for activism. We identify five ways in which The Light encourages participation and activism.

- These findings have real-world implications. While it is clear that the proliferation of recent conspiracy theories is driven by social media, this article suggests that consideration should also be given to offline forms of communication, which can present distinct challenges to policymakers.

\section{Implications}

Recent analyses of conspiracy theories concerned with the Covid-19 pandemic have focused on the ways in which they are disseminated online (see Allington \& Joshi, 2020; Kearney et al., 2020; Jamison et al., 2020). In contrast, much less attention has been paid to how these ideas are communicated via offline media. Indeed, Uscinski (2018) cautions that the online spread of conspiracy theories, while important, should not be over-estimated and although recent research has underlined the significance of social media use as a factor in adherence to conspiracy theories (see Allington et al., 2020), there are many people who lack the ability, or inclination, to engage in online activity (Reisdorf \& Groselj, 2017). Resources such as newsletters, posters, and books can therefore still contribute to the dissemination of conspiracy theories and recent work has identified the use of methods including leafleting and sticker campaigns by Covid-19 conspiracist activists (McNeil-Wilson, 2020).

In this article we address this issue, exploring the ways in which conspiracy theories ${ }^{2}$ are presented and disseminated through offline media. Our approach is qualitative, drawing on a content analysis of The Light, $^{3}$ a newspaper (and self-described "truthpaper") produced and delivered free of charge by activists across the U.K., activities coordinated through a closed Facebook group of over 8,000 members. Its primary focus is on the Covid-19 pandemic and its stated aim to "report the news from across the UK and the rest of the world that is either being unreported (propaganda by omission) or told from the point of view of those it is reporting on, thus making the majority of their output meaningless press releases for those committing crimes against the people on a daily basis." 4 The findings presented here are focused on two areas: (i) the structure and content of The Light, exploring in particular the ways in which it presents conspiracist material; and (ii) how far the content included in The Light actively encourages participation in conspiracy theories and activism.

While our work represents the first time that content analysis has been applied to material of this kind focused on the pandemic, its use to explore belief in conspiracy theories is well established in the literature. For instance, Uscinski \& Parent (2014) analyse letters to the editor of U.S. daily newspapers in establishing the history of conspiracist belief in the U.S. Czech (2019) focuses their analysis on Polish news magazines. Nefes (2015) includes content analysis of antisemitic literature in their work on conspiracy beliefs in Turkey. Wood \& Finlay (2008) explore articles written by prominent members of the British National Party in the aftermath of the London bombings of $7^{\text {th }}$ July 2005 . Extending this approach to address Covid-19 conspiracies has an important role to play in developing existing knowledge of the ways in which conspiracist narratives are constructed and communicated: as Enders et al. (2020) point out,

\footnotetext{
${ }^{2}$ The empirical work underpinning this article draws on Barkun's (2003) definition of conspiracy theories. This suggests conspiracy theories share three features: (i) public issues are seen as Manichean battles between good and evil, (ii) they understand political and social events as resulting from the deliberate action of unseen, malevolent forces, and (iii) the truth about public events is being suppressed.

${ }^{3}$ https://thelightpaper.co.uk/ (accessed 29/06/21)

4 https://www.facebook.com/TheLightPaper/ (accessed 29/06/21)
} 
researchers have yet to codify the structure of conspiracy theories related to Covid-19. Our findings contribute to this aspiration.

We find that conspiracy theories are indeed present in the ways in which The Light discusses the Covid-19 pandemic. However, conspiracist material is presented alongside a range of other content, and The Light includes a significant amount of material which is not focused on the pandemic. Indeed, we identify five discrete categories of content included in The Light, including conspiracy theories focused on Covid-19, unrelated conspiracy theories, non-conspiracist misinformation and content related to Covid19, and other, unrelated news items. The remaining content is primarily taken up with paid advertisements. Consequently, readers encounter conspiracist content embedded within a wide range of other material, in a format that closely resembles a conventional newspaper. As findings by Lazer et al. (2018) indicate, the design of content to mimic mainstream news media in this way can be an effective means of disseminating misinformation.

We also find that a significant amount of content is intended to prompt an active, participatory response in the reader. Articles in The Light do not treat readers as passive recipients of information but adopt a number of devices aimed at directly engaging them in conspiracy theories. For instance, articles frequently attempt to distinguish between a passive majority and those "awake" readers who understand the sinister "true" motives behind public policy measures aimed at addressing the pandemic. As Douglas et al. (2019) suggest, features like these can fulfill an epistemic function, based on individuals' belief that they have gained some rarified knowledge, and can be important factors in motivating adherence to conspiracy theories. Other devices aimed at encouraging participation include explicit prompts to direct action, moral appeals to activism, and encouraging readers to "research" conspiracist material. Interestingly, this latter device occasionally includes the use of puzzles, which require readers to research conspiracist content for successful completion.

These findings present a corrective to much of the recent empirical work in this area through a focus on offline, rather than online, means of disseminating conspiracy theories concerned with Covid-19. Understanding the nature of offline conspiracist material has real-world significance. Public attitudes towards policy responses addressing the Covid-19 pandemic have been characterised by the noncompliance of a relatively small but persistent number of conspiracy theorists (Uscinski et al., 2020; Allington \& Dhavan, 2020). Enders et al. (2020) find that conspiracy theories like these garner greater support than misinformation over the treatment and transmissibility of Covid-19. In the context of the pandemic response, such developments have the potential to cause significant harm. Survey data has connected belief in conspiracy theories over Covid-19 to non-compliance with public health measures such as social distancing measures, mask-wearing, and vaccine take-up (Allington et al., 2020). Clearly, there is potential for the efficacy of policy interventions aimed at mitigating the worst effects of the pandemic to be hindered through engagement with offline material such as The Light. At the same time, these issues have arisen alongside the well-established potential for conspiracy beliefs to promote political polarisation (Sunstein \& Vermeule, 2009), extremism, and political violence (Cohn, 1998; Bartlett \& Miller, 2010).

The Light provides a valuable case for the exploration of these issues for two reasons. First, although it is not possible to accurately establish the extent of its distribution and impact, it may have significant reach-activists involved claim that it has a print run of 100,000 copies (Waterson, 2020), which if true would give it a circulation roughly on a par with the Financial Times (Tobitt \& Majid, 2021), and it is distributed across a wide geographical area in the U.K. (Goodman, 2021). Second, although it is distributed offline, The Light is really a hybrid form of misinformation, taking in both online and offline elements. While it is produced and distributed in print form, these activities are coordinated through social media. It also maintains an online presence, and its articles regularly direct readers to online resources in order to find further information and connect with other, like-minded individuals. This aligns with Jenkins' 
(2006) description of transmedia, where multiple media channels combine to create a highly participatory narrative.

Policymakers and practitioners should therefore consider resources like The Light when shaping strategies for responding to misinformation, alongside a focus on online material. Clearly, The Light provides a means of distributing Covid-19 misinformation that confounds attempts at moderation and fact-checking focused solely on online media. That conspiracist content is included means that, like conspiracy theories spread online, these may be resistant to "debunking" responses due to the tendency of adherents to reject mainstream sources of evidence and expertise in favour of explanations for events which contradict the "official" account (Miller \& Saunders, 2016). But its importance reaches beyond its position as a source of misinformation. Our findings also echo recent work suggesting contemporary forms of conspiracy theory can be participatory, with those involved not simply passive receptors of inaccurate or misleading information, but involved in a process of research and discovery, becoming actively involved in the conspiracy theory itself (see Ahmed et al., 2020). Understanding the ways in which participation is encouraged through resources like The Light is therefore a first step towards the development of responses which directly address the particular challenges raised by Covid-19 conspiracy theories.

\section{Evidence}

At the time of writing, there have been ten issues of The Light, produced monthly from September 2020. Each edition is designed to mimic the style and layout of a conventional newspaper and includes a masthead, logo (a lighthouse), and banner headlines, with each article laid out in columns. It also contains numerous images and charts and includes opinion pieces and interviews alongside news items. Overall, the structure adopted by The Light presents readers with a range of different content, varying in both style and topic. That conspiracist content is encountered alongside other, seemingly unrelated material, means that overall, readers experience the variety of content that might be expected in a daily newspaper.

Each issue includes an average of 36 articles (363 in total), with most editions running to 20 pages long (Issues 1 and 2 include 16 pages, Issue 10 contains 24 pages). The amount of content has more than doubled from Issue 1 (11,846 words) to Issue 10 (24,393 words). Our analysis shows that this content regularly draws on conspiracy theories, with one quarter of the articles published to date coded as containing material aligned to Barkun's (2003) definition. Overwhelmingly, these conspiracy theories are related to Covid-19. For instance, every issue contained at least one article suggesting that the severity of the pandemic has been exaggerated in order to benefit some malign, powerful and secretive group. There was, however, a small amount of conspiracist content which was unrelated to Covid-19 (for example, Issue 6 contains an article outlining a 9/11 conspiracy theory, and Issue 7 includes material connecting water fluoridisation and mind control). Such conspiracy theories did not appear in the first three issues of The Light and conspiracist content in general has become more prevalent with the publication of the more recent issues.

As Table 1 (below) shows, our analysis reveals that the articles published in The Light include five discrete content types. By far the largest proportion of content, almost half, was focused on issues related to the pandemic. Of this, the majority is not conspiracist, although it frequently includes inaccurate or misleading information. This non-conspiracist content is also overwhelmingly both sceptical and negative in tone, and is put across in a range of styles including opinion pieces and news items. Common themes addressed in these articles included concerns over excessive state power and the restriction of individual freedom, questions over vaccine safety and efficacy, and the economic impact of policy aimed at mitigating the pandemic.

Of the remaining content, around $50 \%$ was taken up by paid advertisements and other news items. Commercial content varied widely, ranging from advertisements for conspiracist literature to wedding 
photography. Similarly, some news items addressed issues aligned to conspiracist calls for action (for instance, there have been six articles focused on the need for readers to address child abuse published to date), while others dealt with unrelated topics (for example, Issue 2 included three articles positively assessing Russia's economic performance, with no mention of the pandemic).

Table 1. Types of content in The Light (all issues).

\begin{tabular}{lcccc}
\hline Content type & $\begin{array}{c}\text { Number of } \\
\text { articles }\end{array}$ & $\begin{array}{c}\text { \% of total } \\
\text { content }\end{array}$ & RCA $^{5}$ & ${\text { Cohen's } \boldsymbol{~}^{6}}^{\mathbf{2}}$ \\
\hline Covid-19 conspiracy theory & 77 & 21 & 0.930 & 0.741 \\
Other conspiracy content & 14 & 4 & 0.985 & 0.849 \\
Non-conspiracist Covid-19 content & 100 & 28 & 0.902 & 0.725 \\
Other news item & 72 & 20 & 0.953 & 0.876 \\
Advertising & 100 & 28 & 1.000 & 1.000 \\
\hline
\end{tabular}

Our analysis also suggests that the content included in The Light is intended to encourage readers to participate directly in disseminating conspiracy theories and other forms of activism. While participatory content was not confined to conspiracist articles but was endemic throughout the material included, every article which was coded as conspiracist included some form of participatory device. In total, our analysis identified participatory devices in nearly half of all the content in the issues of The Light published to date (47\%). We identified five techniques employed in The Light to encourage a participatory response (see Table 2).

The most frequently used means of encouraging participation took the form of explicit calls for direct action. Primarily, this was in the form of encouragement to attend rallies and events. However, content also encouraged readers to act by, for instance, refusing to wear face coverings (Issue 6, p. 4) or solely using cash to make payments to avoid government oversight (Issue 8, p. 9). Beyond this, there were also calls to engage in political action, principally through participation in the electoral process, as well as including positive coverage of non-mainstream political parties whose platform broadly reflects the position taken on the pandemic by The Light (see Issue 5, p. 7). Calls for action and participation were also frequently associated with appeals to readers' moral sensibilities. A pervasive trope used in every issue of The Light, this was, for instance, associated with content warning of the effects of public health measures on children (see Issue 1, p. 4) or discussing the dangers of inaction using the language of war and conflict. For example, an opinion piece in Issue 7 (p. 8) cautions that "if we remain silent then we are just a part of the evil which is corrupting and destroying our world."

The Light also includes frequent appeals for readers to "do their own research." Quinn et al. (2020) have previously identified this trope within online communication of conspiracy theories related to the pandemic, and as Amarasingam \& Argentino's (2020) analysis suggests, it has become a common feature of the wider landscape of conspiracism in recent years. Our analysis identified 44 articles which encouraged readers to carry out further research, invariably into sources which took a conspiracist position. As well as direct appeals, this also involved suggesting readers followed the example of individuals who had reached a revelation over the validity of a conspiratorial position through independent study. Frequently, such articles also included suggested sources for readers to use. For

\footnotetext{
${ }^{5}$ Ratio of Coder Agreement

${ }^{6}$ Cohen's (1960) $\kappa$ ("kappa"), a commonly used tool in content analysis which measures whether coder agreement was greater than would have been reached by chance.
} 
instance, in Issue 4, an article on the dangers of Covid-19 vaccines concludes with a list of sources "that can be accessed for free, for further research" (p. 7). Relatedly, six of the issues included a puzzle or game, which required the reader to conduct research into conspiratorial content in order to be successfully completed. In five issues, this puzzle took the form of a combined crossword-wordsearch. However, in Issue 9, it mimicked the popular board game Trivial Pursuit.

Alongside these appeals, frequent reference was made to the importance of being "awake." This device brings readers into an in-group of conspiracy adherents who refute the "official narrative," in contrast with the majority who do not. The state of being "awake" is often put across as being in some way exceptional or virtuous. For example, this is established in the language used to describe those who oppose Covid-19 policy instruments, who are variously described as "heroes" (Issue 2, p. 1) and "lovers of freedom" (Issue 10, p. 6), in contrast to the majority of people, who are "cultists" (Issue 6, p. 6), or have been subjected to "brainwashing" (Issue 2, p. 2). Readers are frequently encouraged to view the acquisition of knowledge over the pandemic's "true" nature as a motivating factor to action, with calls to convert those who are not adherents of the conspiracy theory in question, using "facts and evidence" (Issue 1, p. 9).

Table 2. Participatory content in The Light (all issues).

\begin{tabular}{lcccc}
\hline Content type & $\begin{array}{c}\text { Number of } \\
\text { articles }\end{array}$ & $\begin{array}{c}\text { \% of total } \\
\text { content }\end{array}$ & RCA & Cohen's $\boldsymbol{~}$ \\
\hline Do your own research & 44 & 12 & 0.930 & 0.629 \\
Being "awake" & 44 & 12 & 0.891 & 0.690 \\
Call for direct action & 52 & 14 & 0.853 & 0.629 \\
Moral appeal to action & 24 & 7 & 0.902 & 0.641 \\
Puzzles/games & 6 & 2 & 1.000 & 1.000 \\
\hline
\end{tabular}

\section{Methods}

We draw on a content analysis of The Light, taking in all ten available issues at the time of writing. Adopting this approach to explore conspiracy theories proved useful in a number of ways. First, it was able to shed light on the ways in which conspiracist content is structured by allowing a systematic assessment of the content of conspiratorial material. It is also unobtrusive and is not subject to the kinds of barriers to participation as other methods data collection such as interviews or survey instruments, given the reluctance of participants to describe themselves as "conspiracy theorists" (see Harambam \& Aupers, 2017). It is also able to capture naturalistic expressions of conspiracy belief, rather than collecting data according to pre-determined categories through, for example, the use of questionnaires (Douglas et al., 2019). Finally, it also allows analysis of the structure and presentation of conspiracy theories in a common context across a sustained period of time, in this case over ten months running from September 2020 to June 2021.

In order to answer the first research question, we initially identified the structural features of each issue, including the total number of pages, words, articles, and images. The features of the layout were also identified, in order to establish the presentation of content throughout the issues. Second, a descriptive account of the form and focus of each article was developed through selective coding. This involved identifying the particular style (for instance, opinion pieces or advertisements) and the subject addressed (such as vaccine safety or media bias). Finally, content was coded according to article type, focusing in particular on whether or not the content was conspiracist in nature. Decisions over 
categorisation of conspiracist content were made according to each article's congruence with Barkun's (2003) definition, which is widely used in other studies (see Hameleers, 2021).

In order to answer the second research question, those articles that included some form of conspiratorial content were coded line-by-line, focusing on how far they prompted participation and activism. This involved taking a grounded theory approach, subjecting the data to open coding in order to identify both the prominent themes addressed by content that encouraged participation (for instance, how far moral appeals to action were connected to emotive topics such as mental health) as well as the particular devices that were employed. Finally, the remaining, non-conspiratorial content was subjected to the same process, in order to establish the consistency of participatory devices in both conspiratorial and non-conspiratorial articles. Example coding schemes are included in the Appendix to this article.

Validity checks were applied to a sample of the material, with independent coding carried out by two researchers coding one issue of The Light each, representing $20 \%$ of the total sample of issues-an approach in common with recent content analysis of conspiracy theories (see Hameleers, 2021). These were then tested for inter-coder agreement using two methods. First, a simple ratio of coder agreement (RCA) was established (see Holsti, 1969) as an initial measure of the coherence of the coding. Second, Cohen's (1960) k ("kappa") was employed. Overall, agreement was high, with disagreement only in a small number of cases (e.g., whether or not an article focused on a conspiracy theory). This resulted in $k$ of greater than 0.61 in every case, indicating "substantial agreement" (see Landis \& Koch, 1977). In some cases, for instance, coding content as advertisement or puzzles, coder agreement was unanimous, which can be explained by the clear distinctions between those categories of content and the rest of the material included in the sample.

The limitations of the empirical work are chiefly related to scope. Although a detailed account of the content of The Light is presented here, further cases would establish how far the themes identified are present in other offline literature, or indeed, more widely in online conspiracist material. Equally, further work would be required to fully establish the extent that offline material such as The Light has an impact on attitudes towards the pandemic. Finally, further testing will reveal the significance of the participatory nature of conspiracism identified here. This is an important feature of The Light and tallies with the emerging literature on Covid-19 conspiracism, and we believe that the ways in which contemporary conspiracy theories aim to promote activism warrants further exploration.

\section{Bibliography}

Ahmed, W., Seguí, F. L., Vidal-Alaball, J., \& Katz, M. S. (2020). Covid-19 and the "film your hospital" conspiracy theory: Social network analysis of Twitter data. Journal of Medical Internet Research, 22(10), e22374. https://doi.org/10.2196/22374

Allington, D., \& Joshi, T. (2020). "What others dare not say": An antisemitic conspiracy fantasy and its YouTube audience. Journal of Contemporary Antisemitism, 3(1), 35-53. https://doi.org/10.26613/jca/3.1.42

Allington, D., Duffy, B., Wessely, S., Dhavan, N., \& Rubin, J. (2020). Health-protective behaviour, social media usage and conspiracy belief during the COVID-19 public health emergency. Psychological Medicine, 51(10), 1-7. https://doi.org/10.1017/S003329172000224X

Allington, D., \& Dhavan, N. (2020). The relationship between conspiracy beliefs and compliance with public health guidance with regard to COVID-19. Centre for Countering Digital Hate. https://kclpure.kcl.ac.uk/portal/files/127048253/Allington and Dhavan 2020.pdf

Amarasingam, A., \& Argentino, M. A. (2020). The QAnon conspiracy theory: A security threat in the making. CTC Sentinel, 13(7), 37-44. https://ctc.usma.edu/the-qanon-conspiracy-theory-asecurity-threat-in-the-making/ 
Barkun, M. (2003). A culture of conspiracy: Apocalyptic visions in contemporary America. University of California Press.

Bartlett, J., \& Miller, C. (2010). The power of unreason: Conspiracy theories, extremism and counterterrorism. Demos.

Cohn, N. (1998). Warrant for genocide: The myth of the Jewish world conspiracy and the Protocols of the Elders of Zion. Harper \& Row.

Cohen, J. (1960). A coefficient of agreement for nominal scales. Educational and Psychological Measurement, 20(1). 37-46. https://doi.org/10.1177/001316446002000104

Czech, F. (2019). Saturation of the media with conspiracy narratives: Content analysis of selected Polish news magazines. Środkowoeuropejskie Studia Polityczne, 2, 151-171. https://doi.org/10.14746/ssp.2019.2.9

Douglas, K. M., Uscinski, J. E., Sutton, R. M., Cichocka, A., Nefes, T., Ang, C. S., \& Deravi, F. (2019). Understanding conspiracy theories. Political Psychology, 40(S1), 3-35. https://doi.org/10.1111/pops.12568

Enders, A. M., Uscinski, J. E., Klofstad, C., \& Stoler, J. (2020). The different forms of COVID-19 misinformation and their consequences. Harvard Kennedy School (HKS) Misinformation Review, 1(8). https://doi.org/10.37016/mr-2020-48

Goodman, J. (2021). Covid-19 leaflets: How pandemic disinformation went offline. BBC. https://www.bbc.co.uk/news/56420379

Hameleers, M. (2021). They are selling themselves out to the enemy! The content and effects of populist conspiracy theories. International Journal of Public Opinion Research, 33(1), 38-56. https://doi.org/10.1093/iipor/edaa004

Harambam, J., \& Aupers, S. (2017). 'I am not a conspiracy theorist': Relational identifications in the Dutch conspiracy milieu. Cultural Sociology, 11(1), 113-129. https://doi.org/10.1177/1749975516661959

Holsti, O. R. (1969). Content analysis for the social sciences and humanities. Addison-Wesley.

Jamison, A. M., Broniatowski, D. A., Dredze, M., Sangraula, A., Smith, M. C., \& Quinn, S. C. (2020). Not just conspiracy theories: Vaccine opponents and proponents add to the COVID-19 'infodemic' on Twitter. Harvard Kennedy School (HKS) Misinformation Review, 1(3). https://doi.org/10.37016/mr-2020-38

Jenkins, H. (2006). Convergence culture. New York University Press.

Kearney, M. D., Chiang, S. C., \& Massey, P. M. (2020). The Twitter origins and evolution of the COVID-19 "plandemic" conspiracy theory. Harvard Kennedy School (HKS) Misinformation Review, 1(3). https://doi.org/10.37016/mr-2020-42

Landis, J. R., \& Koch, G. G. (1977). The measurement of observer agreement for categorical data. Biometrics, 33(1), 159-174. https://doi.org/10.2307/2529310

Lazer, D. M., Baum, M. A., Benkler, Y., Berinsky, A. J., Greenhill, K. M., Menczer, F., Metzger, M. J., Nyhan, B., Pennycook, G., Rothschild, D., Schudson, M., Sloman, S. A., Sunstein, C. R., Thorson, E. A., Watts, D. J., \& Zittrain, J. L. (2018). The science of fake news. Science, 359(6380), 1094-1096. https://doi.org/10.1126/science.aao2998

McNeil-Wilson, R. (2020). Framing in times of crisis: Responses to COVID-19 amongst Far Right movements and organisations. ICCT Research Paper. https://icct.nl/app/uploads/2020/06/Framing-in-times-of-crisis-Responses-to-COVID-19amongst-Far-Right-movements-and-organisations.pdf

Miller, J., \& Saunders, K. L. (2016). Conspiracy theories in the United States: More commonplace than extraordinary. Critical Review, 28(1), 127-136. https://doi.org/10.1080/08913811.2016.1172802

Nefes, T. S. (2015). Understanding anti-semitic rhetoric in Turkey through the Sèvres syndrome. Turkish Studies, 16(4), 572-587. https://doi.org/10.1080/14683849.2015.1084876 
Quinn, E. K., Fazel, S. S., \& Peters, C. E. (2020). The Instagram infodemic: Cobranding of conspiracy theories, Coronavirus disease 2019 and authority-questioning beliefs. Cyberpsychology, Behavior, and Social Networking, 24(8), 573-577. https://doi.org/10.1089/cyber.2020.0663

Reisdorf, B. C., \& Groselj, D. (2017). Internet (non-) use types and motivational access: Implications for digital inequalities research. New Media \& Society, 19(8), 1157-1176. https://doi.org/10.1177/1461444815621539

Sunstein, C. \& Vermeule, A. (2009). Conspiracy theories: Causes and cures. Journal of Political Philosophy, 17(2), 202-227. https://doi.org/10.1111/j.1467-9760.2008.00325.x

Tobitt, C., \& Majid, A. (2021). National press ABCs: Bulks help the FT and i paper to keep circulations up in July 2021. PressGazette. https://www.pressgazette.co.uk/most-popular-newspapers-uk-abcmonthly-circulation-figures/

Uscinski, J. (2018). Down the rabbit hole we go!. In Conspiracy theories and the people who believe them (pp. 1-32). Oxford University Press. https://doi.org/10.1093/oso/9780190844073.001.0001

Uscinski, J. E., \& Parent, J. M. (2014). American conspiracy theories. Oxford University Press.

Uscinski, J. E., Enders, A. M., Klofstad, C. A., Seelig, M. I., Funchion, J. R., Everett, C., Wuchty, S., Premaratne, K., \& Murthi, M. N. (2020). Why do people believe COVID-19 conspiracy theories?. Harvard Kennedy School (HKS) Misinformation Review, 1(3). https://doi.org/10.37016/mr-2020-015

Waterson, J. (2020). How an anti-lockdown 'truthpaper' bypasses online factcheckers. The Guardian. https://www.theguardian.com/world/2020/nov/27/truthpaper-the-anti-lockdown-newspaperbypassing-online-fact-checkers

Wood, C., \& Finlay, W. M. L. (2008). British National Party representations of Muslims in the month after the London bombings: Homogeneity, threat, and the conspiracy tradition. British Journal of Social Psychology, 47(4), 707-726. https://doi.org/10.1348/014466607X264103 


\section{Funding}

No funding was received for this study.

\section{Competing interests}

The authors have no competing interests to declare.

\section{Ethics}

None. The study did not require an institutional review. The study did not involve human subjects.

\section{Copyright}

This is an open access article distributed under the terms of the Creative Commons Attribution License, which permits unrestricted use, distribution, and reproduction in any medium, provided that the original author and source are properly credited.

\section{Data availability}

All materials needed to replicate this study are available via the Harvard Dataverse:

https://doi.org/10.7910/DVN/WAG3V1 


\section{Appendix: Example coding schemes}

Example coding schemes used to categorize content according to (i) content type and (ii) devices used to promote participation and activism.

Example coding scheme 1: Content type

\begin{tabular}{|l|l|}
\hline Covid-19 conspiracy theories & $\begin{array}{l}\text { Uses conspiracy theories (according to Barkun's } \\
\text { (2003) definition) to explain or make sense of the } \\
\text { pandemic, including policy responses. }\end{array}$ \\
\hline Other conspiracist content & $\begin{array}{l}\text { Uses conspiracy theories (according to Barkun's } \\
\text { (2003) definition) to explain or make sense of an } \\
\text { unrelated event or issue. }\end{array}$ \\
\hline $\begin{array}{l}\text { Non-conspiracist Covid-19 misinformation and } \\
\text { content }\end{array}$ & $\begin{array}{l}\text { Content related to the pandemic and aligned policy } \\
\text { responses and phenomena that does not meet } \\
\text { Barkun's (2003) definition }\end{array}$ \\
\hline Other non-conspiracist news items & $\begin{array}{l}\text { News items unrelated to the pandemic that do not } \\
\text { meet Barkun's (2003) definition }\end{array}$ \\
\hline Advertisements & $\begin{array}{l}\text { Content in the form of paid-for or donated } \\
\text { advertising space }\end{array}$ \\
\hline
\end{tabular}

Example coding scheme 2: Participatory content

\begin{tabular}{|l|l|}
\hline Do your own research & $\begin{array}{l}\text { Content calls for readers to research issues for } \\
\text { themselves and/or to find information that refutes } \\
\text { the "official narrative." }\end{array}$ \\
\hline Being "awake" & $\begin{array}{l}\text { Content brings readers into an "in group" of } \\
\text { conspiracy adherents who refute the "official } \\
\text { narrative," contrasted with those who do not. }\end{array}$ \\
\hline Call for direct action & $\begin{array}{l}\text { Content calls for readers to participate in some form } \\
\text { of direct action (such as attending a protest march } \\
\text { or distributing The Light). }\end{array}$ \\
\hline Moral appeal to action & Content frames participation as a moral imperative \\
\hline Puzzles/games & $\begin{array}{l}\text { Content in the form of a puzzle/game that requires } \\
\text { the reader to engage with conspiracist content }\end{array}$ \\
\hline
\end{tabular}

